\title{
Arang Aktif Kayu Leucaena Leucocephala sebagai Adsorben Minyak Goreng Bekas Pakai (Minyak Jelantah)
}

\author{
H. N. Muhammad1 ${ }^{*}$, F. Nikmah², N. U. Hidayah ${ }^{3}$, A. K. Haqiqi ${ }^{4}$ \\ Program Studi Tadris IPA, Institut Agama Islam Negeri Kudus, Indonesia \\ *Email: hafidzim3@gmail.com
}

Received: Junei 16th, 2020. Accepted: August 22nd, 2020. Published: August 31'st, 2020

\begin{abstract}
Abstrak
Minyak goreng merupakan kebutuhan pokok bagi kehidupan manusia. Alternatif pengolahan minyak goreng bekas adalah melalui proses adsorpsi dengan arang aktif kayu leucaena leucocephala. Penelitian ini bertujuan untuk memanfaatkan arang aktif kayu leucaena leucocephala sebagai adsorben minyak goreng bekas pakai. Arang aktif dari kayu leucaena leucocephala dapat menurunkan kadar asam lemak bebas dan bilangan peroksida minyak goreng sebelum dan sesudah penggorengan secara berulang-ulang sehingga minyak jelantah dapat dipakai kembali. Metode yang digunakan dalam penelitian yaitu metode eksperimen. Uji coba dilakukan dengan mencampurkan arang aktif kayu leucaena leucocephala dengan minyak jelantah. Komposisi pada arang aktif $75 \%$, sedangkan pada minyak jelantah 25\% dalam waktu satu setengah jam. Penelitian membuktikan bahwa arang aktif dapat memperbaiki kualitas minyak jelantah dengan menurunkan kadar asam lemak sehingga menjadikan warna dari minyak jelantah menjadi lebih jernih. Arang aktif kayu leucaena leucocephala dapat digunakan sebagai alternatif adsorben minyak dan perlu dilakukan penelitian untuk jenis minyak yang lain.
\end{abstract}

\begin{abstract}
Cooking oil is a basic need for human life. Alternative processing of used cooking oil is through the adsorption process with leucaena leucocephala activated charcoal. This study aims to utilize leucaena leucocephala activated charcoal as an adsorbent of used cooking oil. Activated charcoal from leucaena leucocephala can reduce levels of free fatty acids and peroxide
\end{abstract}


numbers of cooking oil before and after frying repeatedly so that used cooking oil can be reused. The method used in the study is the experimental method. Data collection was carried out by mixing leucaena leucocephala activated charcoal with used cooking oil. The composition of activated charcoal is $75 \%$, while used cooking oil is $25 \%$ in one and a half hours. Research shows that activated charcoal can improve the quality of used cooking oil by lowering fatty acid levels, making the color of used cooking oil clearer. Leucaena leucocephala activated charcoal can be used as an alternative to oil adsorbent and research is needed for other types of oil. C2020PERJ

Keywords: leucaena leucocephala charcoal; adsorbents; used cooking oil.

\section{PENDAHULUAN}

Salah satu kebutuhan konsumsi manusia adalah minyak goreng yang dimanfaatkan sebagai bahan pengolah makanan. Minyak goreng merupakan minyak yang berasal dari tumbuh-tumbuhan maupun hewan yang dibuat secara sintetik dengan cara dimurnikan kemudian digunakan untuk menggoreng makanan. Penggunaan minyak goreng pada proses penggorengan secara terus menerus, berulangulang pada suhu tinggi $\left(160-180^{\circ} \mathrm{C}\right)$, dan disertai kontak udara dan air akan mengakibatkan reaksi degradasi pada minyak goreng dan menghasilkan berbagai senyawa hasil reaksi (Yustinah \& Hartini, 2011).

Proses pemanasan yang tinggi pada minyak goreng akan menghasilkan asam lemak bebas. Selain itu, senyawa karbonil dan peroksida juga akan dihasilkan saat proses penggorengan yang dapat menyebabkan keracunan kronis pada manusia (Hidayati, Masturi, \& Yulianti, 2016). Setelah digunakan berulang kali dalam penggorengan, minyak akan berubah warna. Hal ini dikarenakan adanya proses oksidasi dan polimerisasi. Proses tersebut akan merusak sebagian vitamin dan asam lemak esensial dalam minyak goreng sehingga mengakibatkan keracunan dalam tubuh (Rahayu, Purnavita, \& Sriyana, 2014).

Menurut data dari Pusat Data dan Sistem Informasi Pertanian, terjadi peningkatan konsumsi minyak dari tahun 2012 hingga tahun 2017 yaitu sebesar 7,44\% dengan jumlah 1,83 juta ton menjadi 2,36 juta ton. Penggunaan minyak goreng tersebut paling banyak dimanfaatkan untuk konsumsi rumah tangga. Total konsumsi ini diperoleh dari angka per kapita (susenas) dikalikan dengan jumlah penduduk. Selain minyak goreng konsumsi, minyak goreng sawit juga mengalami peningkatan yaitu 
1,9 juta ton menjadi 2,45 juta ton dari tahun 2012 sampai tahun 2017 (Sabarella et al., 2017).

Minyak yang baik adalah yang mengandung asam lemak tak jenuh yang lebih banyak dibanding asam lemak jenuhnya. Minyak goreng juga berfungsi untuk menghantarkan panas, menambah nilai gizi dan kalori dalam pangan, serta menambah rasa gurih. Konsumen lebih memilih makanan praktis dan harga yang lebih murah. Oleh karena itu, banyak pedagang yang menekan jumlah pengeluaran bahan dan melakukan upaya untuk mendapatkan lebih banyak keuntungan. Salah satu upaya yang dilakukan adalah dengan menggunakan minyak goreng berulang kali. Minyak goreng yang digunakan berulang kali disebut minyak jelantah.

Tingginya penggunaan minyak goreng membuat kebutuhan minyak goreng meningkat dari tahun ke tahun sehingga banyak masyarakat menggunakan minyak goreng berulang kali (Masyithah, Aritonang, \& Gultom, 2018). Kebiasaan masyarakat menggunakan minyak jelantah akan menjadi sumber penyakit. Hal ini disebabkan minyak yang sudah dipakai berkali-kali akan menjadi sarang perkembangbiakan berbagai jenis bakteri, sehingga menyebabkan penyakit seperti obesitas, peningkatan risiko kanker, dan risiko penyakit degeneratif. Minyak jelantah dikatakan limbah karena dapat merusak lingkungan sekitar (Suirta, 2014) dan dapat menimbulkan penyakit bagi yang mengkonsumsi makanan dari minyak jelantah (Hidayati et al., 2016).

Pengolahan minyak jelantah perlu dilakukan untuk meningkatkan kualitas dan mengurangi dampak kesehatan yang ditimbulkan dari penggunaan minyak tersebut. Salah satu cara pengolahan minyak jelantah adalah dengan menggunakan adsorben agar minyak jelantah kembali jernih sehingga mutunya dapat dipertahankan.

Penelitian sebelumnya yang telah dilakukan untuk pemurnian minyak goreng dengan adsorben berbahan alam atau limbah pertanian, seperti arang dari ampas tebu (Saputro \& Retnaningrum, 2016), arang aktif dari sabut kelapa (Abdullah, Saleh, \& Novianty, 2014)(Puspita Melfi, M. Lutfi Firdaus, \& Nurhamidah, 2017) dan arang aktif dari kulit salak (Mangallo, Susilowati, \& Wati, 2014). Adsorben merupakan cara yang sederhana dan efisien dalam pemurnian minyak jelantah (Maskan \& Bağci, 2003). Arang aktif adalah arang yang memiliki konfigurasi atom karbon yang dibebaskan dari ikatannya dengan cara menggabungkan dengan unsur lain atau dengan menyisipkan pengotor (impuritas), sehingga permukaan karbon menjadi bersih atau aktif (Nasir, Nurhaeni, \& Musafira, 2014). Salah satu bahan yang digunakan dalam pembuatan 
arang yaitu kayu leucaena leucocephala. Oleh karena itu, penelitian ini dilakukan untuk memanfaatkan kayu leucaena leucocephala. Kayu tersebut dijadikan arang sebagai adsorben minyak goreng bekas pakai (minyak jelantah).

\section{METODE}

Penelitian ini menggunakan metode eksperimen. Data-data diperoleh dari percobaan. Peralatan yang digunakan yaitu arang aktif kayu leucaena leucocephala, minyak goreng bekas pakai (minyak jelantah), gelas bening, sendok, dan saringan. Langkah yang dilakukan adalah sebagai berikut:

1. Pembuatan arang aktif kayu leucaena leucocephala. Kayu leucaena leucocephala diambil dan dikeringkan. Setelah kering, kemudian dibakar hingga menjadi arang.

2. Preparasi alat dan bahan dengan menyiapkan minyak goreng bekas pakai dan arang aktif kayu leucaena leucocephala. Selanjutnya minyak jelantah dimasukkan ke dalam gelas bening.

3. Proses pemurnian minyak goreng bekas, dilakukan dengan:

a) menyiapkan minyak goreng bekas pakai (minyak jelantah) kedalam gelas bening;

b) memastikan bahwa minyak jelantah bersih dari sisa penggorengan, kemudian memasukkan arang aktif kayu leucaena leucocephala dengan komposisi arang aktif $75 \%$ dan minyak jelantah $25 \%$;

c) mengaduk rata hingga arang tercelup pada minyak goreng bekas pakai;

d) setelah diaduk (tercelup), diamkan kurang lebih selama satu setengah jam sehingga didapatkan hasil pemurnian minyak jelantah tersebut.

\section{HASIL DAN PEMBAHASAN}

Hasil percobaan menggunakan arang aktif kayu leucaena leucocephala sebagai adsorben minyak jelantah mampu digunakan untuk menjernihkan minyak jelantah. Karbon yang terkandung pada arang kayu leucaena leucocephala memiliki zat yang dapat menyerap komponen tertentu dari suatu fase fluida yang disebut zat adsorben (Siaka, Dona, Putri, \& Suarsa, 2017).

Penelitian ini diawali dengan pembuatan arang aktif yang digunakan sebagai adsorben untuk penjernihan minyak jelantah. Arang yang berkualitas baik adalah arang yang memiliki nilai kalor yang tinggi sehingga tidak mengeluarkan banyak asap dalam proses pembakaran. Nilai kalor yang tinggi sangat dipengaruhi oleh kadar air.

Tahapan pembuatan arang aktif yaitu: 
a. Dehidrasi, yaitu menghilangkan air.

b. Karbonisasi, yaitu pemecahan bahan-bahan organik menjadi karbon.

c. Aktifasi, yaitu proses penguraian dari arang dan perluasan pori-pori.

Teknik dan proses pembuatan arang sebagai berikut:

a. Proses kimia: arang aktif dicampur dengan bahan kimia, kemudian dikeringkan.

b. Proses fisika: arang aktif dikarbonisasi terlebih dahulu, kemudian dihaluskan dan diaktifasi dengan cara pemanasan yang disertai pengaliran uap.

Bahan baku yang digunakan dalam pembuatan arang aktif adalah kayu leucaena leucocephala (kayu petai cina). Kayu leucaena leucocephala dikeringkan sampai benar-benar kering kemudian dibakar hingga menjadi arang. Proses ini membutuhkan waktu yang tidak sebentar.

Arang kayu leucaena leucocephala digunakan sebagai arang aktif bahan adsorben untuk menjernihkan minyak jelantah. Arang aktif ini merupakan produk dari proses karbonisasi kayu leucaena leucocephala yang sebagian besar komponennya merupakan karbon, kemudian dilakukan pemrosesan secara lanjut dengan pemanasan tinggi sehingga mampu membuka pori-pori arang (Siaka et al., 2017). Arang aktif leucaena leucocephala tersebut dapat diaplikasikan sebagai adsorben. Adsorben adalah zat padat yang dapat menyerap komponen tertentu dari suatu fase fluida. Proses penjernihan minyak dilakukan memasukkan arang kayu leucaena leucocephala ke dalam wadah yang sudah terdapat minyak jelantah. Minyak yang akan di jernihkan harus minyak jelantah yang sudah dihilangkan sisa-sisa ampas yang ada di dalam minyak. Tujuannya agar proses penjernihan dapat dilakukan dengan baik. Pada proses penjernihan, arang direndam ke dalam minyak jelantah kurang lebih selama satu setengah jam. Selama kurun waktu tersebut arang akan melakukan adsorbsi terhadap kandungan yang terdapat dalam minyak jelantah. Hasil yang didapatkan warna minyak jelantah menjadi lebih jernih dari sebelumnya, seperti yang terlihat pada Gambar 1.
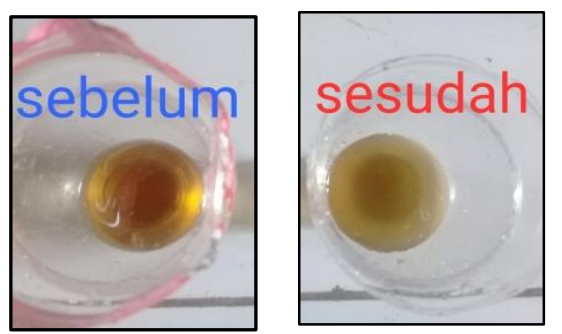

Gambar 1. Hasil penjernihan minyak jelantah

Berdasarkan data percobaan yang diperoleh, terlihat perbedaan miyak jelantah sebelum dan setelah proses penjernihan. Minyak jelantah yang awalnya keruh, setelah melalui 
proses pemurnian menjadi agak jernih dari sebelumnya.

Warna minyak jelantah setelah diberikan adsorben menjadi lebih jernih karena adsorben mampu menyerap warna minyak jelantah yang diakibatkan oleh hidrolisis dan proses oksidasi. Hal ini sesuai dengan penelitian Pari, Tohir, Mahpudin, \& Ferry, (2006) yang menggunakan arang aktif serbuk gergaji kayu sebagai adsorben minyak jelantah dengan peningkatan kecerahan warna dari $13,98 \%$ menjadi $16,02 \%$ setelah dijernihkan.

Warna yang gelap pada minyak jelantah merupakan akibat dari komponen minyak seperti karotenoid dan vitamin yang teroksidasi karena bereaksi dengan peroksida, juga kemungkinan terdapat bahan yang dimasak terlarut dalam minyak (Yustinah \& Hartini, 2011). Penyerapan warna minyak jelantah oleh adsorben yang berasal dari arang aktif ini karena partikel-partikel yang terlarut dalam minyak goreng penyebab kekeruhan akan terserap pada permukaan adsorben. Penelitian lain yang serupa juga telah dilakukan oleh Rahayu et al. (2014) dengan menggunakan adsorben sabut dan tempurung kelapa. Hasil penelitian tersebut menunjukkan adsorben sabut dan tempurung kelapa dapat menyerap senyawa warna pada minyak jelantah dengan berkurangnya tingkat kekeruhan (Rahayu et al., 2014).
Minyak jelantah mengandung kandungan lemak yang kurang baik. Penjernihan minyak jelantah pada penelitian ini diharapkan mampu mengurangi kandungan kadar lemak jahat dalam minyak jelantah sehingga minyak dapat digunakan kembali dengan aman. Pada penelitian ini terbukti bahwa kualitas minyak jelantah dapat diperbaiki dengan arang aktif, yaitu dengan menurunkan kadar asam lemak yang terkandung di dalam minyak sehingga menjadikan warna lebih jernih.

\section{KESIMPULAN}

Arang aktif kayu leucaena leucocepha dapat digunakan sebagai adsorben minyak goreng bekas pakai. Arang aktif mampu menurunkan kadar asam lemak bebas dan bilangan peroksida yang menjadikan minyak goreng setelah dipakai berulang-ulang dapat digunakan kembali dengan aman. Pemurnian minyak jelantah dengan adsorben arang aktif kayu leucaena leucocepha sangat sederhana untuk dilakukan dan perlu dilakukan penelitian lebih lanjut untuk diterapkan pada jenis minyak yang lain.

\section{DAFTAR PUSTAKA}

Abdullah, A., Saleh, A., \& Novianty, I. 2014. Adsorpsi Karbon Aktif Dari Sabut Kelapa (Cocos nucifera) terhadap Penurunan Fenol. Al Kimia: 1-2. 
Hidayati, F. C., Masturi, \& Yulianti, I. 2016. Pemurnian Minyak Goreng Bekas Pakai (Jelantah) dengan Menggunakan Arang Bonggol Jagung. JIPF (Jurnal Ilmu Pendidikan Fisika), 1(2): 67. https://doi.org/10.26737/jipf. v1i2.67

Mangallo, B., Susilowati, \& Wati, S. I. 2014. Efektivitas Arang Aktif Kulit Salak pada Pemurnian Minyak Goreng Bekas. Chem. Prog., $\quad 7(2)$ : 101. https://doi.org/10.36465/jkbt h.v9i1.101

Maskan, M., \& Bağ ci, H. I. 2003. Effect of Different Adsorbents on Purification of Used Sunflower Seed Oil Utilized for Frying. European Food Research and Technology, 217(3): 215-218. https://doi.org/10.1007/s0021 7-003-0731-2

Masyithah, C., Aritonang, B., \& Gultom, E. 2018. Pembuatan Arang Aktif dari Limbah Kulit Durian sebagai Adsorben pada Minyak Goreng Bekas Untuk Menurunkan Kadar Asam Lemak Bebas dan Bilangan Peroksida. Jurnal Kimia Saintek Dan Pendidikan, II(2): 66-75.

Nasir, N. S. W., Nurhaeni, \& Musafira. 2014. Pemanfaatan Arang Aktif Kulit Pisang Kepok (Musa Normalis) sebagai Adsorben untuk Menurunkan Angka Peroksida dan Asam Lemak Bebas Minyak Goreng Bekas. Journal of Natural Science, 3(1): 18-30.

Pari, G., Tohir, D., Mahpudin, \&
Ferry, J. 2006. Arang Aktif Serbuk Gergaji Kayu sebagai Bahan Adsorben pada Pemurnian Minyak Goreng Bekas (Activated Charcoal From Wood Sawdust As Adsorbent Material For Frying Oil Refinery). Jurnal Penelitian Hasil Hutan, 24(4): 309-322.

Puspita Melfi, M. Lutfi Firdaus, \& Nurhamidah. 2017.

Pemanfaatan Arang Aktif Sabut Kelapa Sawit sebagai Adsoben Zat Warna Sintetis Reactive Red-120 dan Direct Green -26. Alotrop, 1(1): 75-79.

Rahayu, L., Purnavita, S., \& Sriyana, H. 2014. Potensi Sabut Dan Tempurung Kelapa Sebagai Adsorben Untuk Meregenerasi Minyak Jelantah. Jurnal Momentum Unwahas, 10(1).

Sabarella, Komalasari, W. B., Wahyuningsih, S., Manurung, M., Herwulan, M., Sehusman, Rinawati. 2017. Konsumsi Pangan. Buletin Triwulanan Konsumsi Pangan, 54. Retrieved from

http://epublikasi.setjen.pertan ian.go.id/epublikasi/buletin/ konsumsi/2017/Buletin_Kons umsi_Pangan_Semester_2_201 7/files/assets/basic$\mathrm{html} /$ page2.html

Saputro, S., \& Retnaningrum, A. 2016. Penggunaan Serbuk Gergaji Kayu Jati Sebagai Absorben Ion Logam dan Analisisnya Menggunakan Solid-Phase

Spectrophotometry. Seminar 
Nasional Pendidikan Sains, 2.

Siaka, I. M., Dona, P., Putri, O., \& Suarsa, I. W. 2017. Pemanfaatan Arang Aktif dari Batang Tanaman Gumintir (Tagetes erecta) sebagai Adsorben Logam Berat Pb (II) dan Cd (II) dengan Aktivator $\mathrm{NaOH}$. E-Journal Of Applied Chemistry, 5(2): 120-130.

Suirta, I. W. 2014. Produksi Biodisel dari Minyak Jelantah Menggunakan Katalis Asam padat (Nafion/SiO2). Eksergi, 10(2): $\quad 52$. https://doi.org/10.31315/e.v1 $0 \mathrm{i} 2.341$

Yustinah, \& Hartini. 2011. Adsorbsi Minyak Goreng Bekas Menggunakan Arang Aktif dari Sabut Kelapa. Pengembangan Teknologi Kimia Untuk Pengolahan Sumber Daya Alam Indonesia, B05-1-B05-5. 